\title{
Pattern of Epithelial Cell Cycling in Hydra
}

\author{
Thomas W. Holstein, ${ }^{1}$ Engelbert Hobmayer, ${ }^{2}$ and Charles N. David \\ Department of Zoology, University of Munich, Luisenstrasse 14, Munich 2, Germany
}

Accepted August 30, 1991

\begin{abstract}
We have investigated the spatial pattern of epithelial cell cycling in a mutant strain of Hydra magnipapillata (sf-1). This strain has temperature sengitive interstitial stem cells and thus polyps containing only epithelial cells can be obtained by growth at the restrictive temperature. Epithelial animals were pulse labeled with the thymidine analog 5 '-bromo-2'-deoxyuridine (Brdu) and stained with anti-Brdu antibody to visualize $\mathbf{S}$ phase cells. Our results indicate that Brdu-labeled cells are broadly and fairly evenly distributed along the body column. Feeding stimulates a rapid decrease and then an increase in labeled cells in gastric tissue; labeled cells in the head are not affected. Starvation leads to a twofold decrease in labeled cells in the gastric region; the density of labeled cells in head tissue remains similar to that in well-fed animals. During bud formation the number of labeled epithelial cells increases significantly in the evaginating bud. During head regeneration the number of labeled cells declines sharply during the first $12 \mathrm{hr}$ and then increases to a density typical of head tissue by $24-36 \mathrm{hr}$ of regeneration. The results indicate the release of signals by feeding and regeneration which inhibit mitosis. By contrast head tissue and developing buds express signals stimulating mitosis. Thus changes in epithelial cell cycling in hydra are closely correlated with morphogenetic events as well as with feeding stimuli. (C) 1991 Academic Press, Inc.
\end{abstract}

\section{INTRODUCTION}

In many organisms cell proliferation plays an important role in morphogenesis (Summerbell et al., 1973; French, 1984; Bryant and Simpson, 1984; Wolpert and Stein, 1984). By contrast morphogenesis in hydra has been generally assumed to occur without major changes in cell proliferation (Gierer, 1977; Graf and Gierer, 1980; Bode and Bode, 1984). For example, it has been shown that cell epithelia can evaginate while showing no differences in cell proliferation compared to nonevaginating tissue (Campbell, 1967a; Clarkson and Wolpert, 1967) and that evagination can proceed even in the absence of cell proliferation (Diehl and Burnett, 1965; Webster and Hamilton, 1972). In the older literature, however, there are reports that cell mitoses are more numerous in the subhypostomal region, which was taken as evidence for a "growth zone" (Burnett, 1966).

We have reinvestigated epithelial cell proliferation in hydra using a new technique for visualizing $S$ phase cells labeled with Brdu in whole mounts (Plickert and Kroiher, 1988). Brdu (5'-bromo-2'-deoxyuridine) is a thymidine analog which is incorporated into DNA during $S$ phase and which can be visualized with a specific monoclonal antibody (Anti-Brdu) (Gratzner, 1982; Dolbeare et al., 1983). Since the hydra cell cycle lacks G1 (after

\footnotetext{
1 To whom correspondence should be addressed.

${ }^{2}$ Current address: Department of Developmental Geneties, $\mathrm{Na}$ tional Institute of Genetics, YATA 1, 111 Mishima, Shizuoka 411, Japan.
}

mitosis the daughter cells directly enter S phase; David and Campbell, 1972; Campbell and David, 1974), the pattern of Brdu-labeled cells reflects the pattern of mitoses integrated over the length of an $\mathrm{S}$ phase (i.e., $12 \mathrm{hr}$; David and Campbell, 1972).

Our results indicate that the distribution of $S$ phase cells in epithelial hydra is not uniform along the animal. They also indicate that feeding, head regeneration, and bud formation can all lead to rapid and significant changes in cycling behavior. The results suggest the existence of endogenous signals, which are released by feeding and by morphogenetic events and which either stimulate or inhibit epithelial cell cycling.

\section{MATERIALS AND METHODS}

Strains and culture conditions. A mutant strain of $\mathrm{Hy}$ dra magnipapillata, sf-1 (self feeder 1) was used in this study (Sugiyama and Fujisawa, 1977). This strain has temperature sensitive interstitial cells: animals cultured at $18^{\circ} \mathrm{C}$ contain normal levels of interstitial cells, animals cultured at $25^{\circ} \mathrm{C}$ lose their interstitial cells within $24-48 \mathrm{hr}$ (Marcum et al., 1980). Large budless animals were used for all experiments except experiments involving bud formation. Experimental animals were fed daily with freshly hatched brine shrimp nauplii and cultured in M solution (Sugiyama and Fujisawa, 1977) at $18^{\circ} \mathrm{C}$. All experiments were carried out in a constant temperature room at $18 \pm 0.5^{\circ} \mathrm{C}$.

Definition of body regions. Head refers to hypostome, tentacle base, and subhypostomal region (distal $\frac{1}{8}$ of 
body column), where tentacle tissue is initially formed (Hobmayer et al., 1990a,b). Gastric region refers to entire body column excluding head and peduncle; it includes the presumptive budding region in animals lacking developing buds; in animals with buds, buds were excised and analyzed separately. Peduncle refers to tissue below the budding region, including the basal disc.

Identification of cell types by maceration. The cell composition and cell number in hydra tissue were determined in macerated cell preparations (David, 1973). For the experiments reported here $10-20$ animals were used per sample and 500-1000 cells were counted in each sample.

Elimination of interstitial cells. To eliminate interstitial cells sf- 1 animals were cultured at $24^{\circ} \mathrm{C}$. Within 24 $\mathrm{hr}$ after the temperature increase, nearly all $\mathrm{S}$ phase interstitial cells were eliminated (Marcum et al., 1980). Nerve cells, nematocytes, and gland cells also decreased in number over several days in heat-treated sf-1 animals (Marcum et al., 1980). Due to the loss of nerve cells and nematocytes animals become unable to eat by themselves about 10 days after heat treatment. The experiments reported here were carried out between 3 and 5 days after the elimination of interstitial cells; all animals used for the experiments had normal feeding behavior.

Labeling with Brdu. Hydra were labeled with the thymidine analog 5'-bromo-2'-deoxyuridine (Brdu, Sigma) by incubating in a $5 \mathrm{mM}$ Brdu solution; regenerating animals and buds were labeled by injecting $\operatorname{Brdu}(5 \mathrm{mM})$ in to the gastric cavity using a polyethylene needle (David and Campbell, 1972). One hour after labeling, animals were either processed for whole mount preparations or macerated for cell preparations on gelatin coated slides (David, 1973). For whole mount preparations the animals were anesthesized in $2 \%$ urethane (Serva) in M solution ( $\max 1 \mathrm{~min}$ ); the relaxed and elongated hydra were fixed with $75 \%$ ethanol $(12 \mathrm{hr})$.

Immunocytochemical localization of Brdu. The incorporated Brdu was localized with a specific monoclonal antibody "Anti-Brdu" (Gratzner, 1982). Fixed animals were washed with $\mathrm{PBS}(3 \times 20 \mathrm{~min})$, heated in a water bath $\left(80^{\circ} \mathrm{C}\right)$ for at least $30 \mathrm{~min}$, exposed to $2 \mathrm{~N} \mathrm{HCl}(30$ $\mathrm{min})$, rinsed with PBS $(3 \times 20 \mathrm{~min})$, and incubated with the monoclonal antibody Anti-Brdu (Becton-Dickinson; diluted $1: 20$ with PBS containing $0.1 \%$ Tween 20 and $1 \%$ BSA). The binding of the monoclonal antibody to the DNA was visualized either with an anti-mouse-IgGFITC (Tago, California; 1:50 in PBS, 1\% BS $\Lambda, 0.02 \%$ azide) or with an anti-mouse-IgG-alkaline phosphatase (AP) complex (Promega; 1:7500 in TBST); for the alkaline phosphatase reaction animals were incubated in a AP substrate solution of $66 \mu \mathrm{l}$ nitro blue tetrazolium
(NBT, Sigma) (50 mg in $1 \mathrm{ml} 70 \%$ dimethylformamide) and $33 \mu \mathrm{l}$ 5-bromo-4-chloro-3-indolylphosphate $p$-toluidine salt (BCIP, Sigma) (50 mg in $1 \mathrm{ml} \mathrm{100 \%} \mathrm{dimethyl-}$ formamid) diluted in $10 \mathrm{ml} \mathrm{AP}$ buffer $(100 \mathrm{~m} M$ Tris, $\mathrm{pH}$ $9.7 ; 100 \mathrm{mM} \mathrm{NaCl} ; 5 \mathrm{mM} \mathrm{MgCl}_{2}$ ) for 5-10 min. The procedure for macerated cell preparations was identical, except that there was no heat treatment prior to denaturation with HCL.

Microscopy. Whole mounts and macerated cells were observed with a Leitz Dialux 20 microscope equipped with epifluorescence attachment and filterblock 12 (BP 450-490 nm, RKP 510, LP $515 \mathrm{~nm}$ ). For documentation by camera lucida drawings and photography the following lenses (Leitz) were used: NPL Fluotar 6.3/0.15, NPL Fluotar 10/0.45 oil phaco, NPL Fluotar 25/0.75 oil phaco, NPL Fluotar 40/1.30 oil phaco, and NPL Fluotar 100/ 1.32 oil phaco. Fluorescence photography was performed with Kodak T-Max 400 film; photography of AP specimens was performed using a green filter and AgfaOrtho 25 film developed in Kodak Technical Pan developer.

\section{RESUL'S}

\section{Brdu Labeling Pattern in Epithelial Polyps}

To analyze the labeling pattern of epithelial cells, sf-1 polyps were heat treated to eliminate interstitial cells (see Materials and Methods). Treated polyps ( $24 \mathrm{hr}$ after last feeding) were pulse labeled with Brdu and labeled epithelial cells were identified by staining with anti Brdu antibody (Fig. 1).

Because hydra cells do not have a G1 phase, the immediate product of mitosis is a pair of daughter cells in $\mathrm{S}$ phase. Such pairs of daughter cells were clearly detectable in the gastric region of Brdu-labeled hydra. Even when the density of dividing cells was high, it was usually possible to identify daughter cell pairs because of the identical extent of Brdu incorporation in both cells of a pair (Fig. 2).

Brdu-labeled cells were distributed fairly evenly over the entire body column. The density of labeled cells was similar in the head and in the gastric region; it was slightly lower in the peduncle (Fig. 1). This visual impression was confirmed by quantitative measurements of the labeling index in macerated cell preparations. The labeling index was 0.17 in the head and 0.15 in the gastric region (see Fig. 4); the labeling index of cells in the peduncle was, however, only 0.07 .

Tentacles and basal disk contained no labeled epithelial cells. Cells in both regions are arrested in G2 and terminally differentiated to battery cells or basal disk mucous cells (Dübel et al., 1987). In some polyps the border between labeled and unlabeled cells at the base 

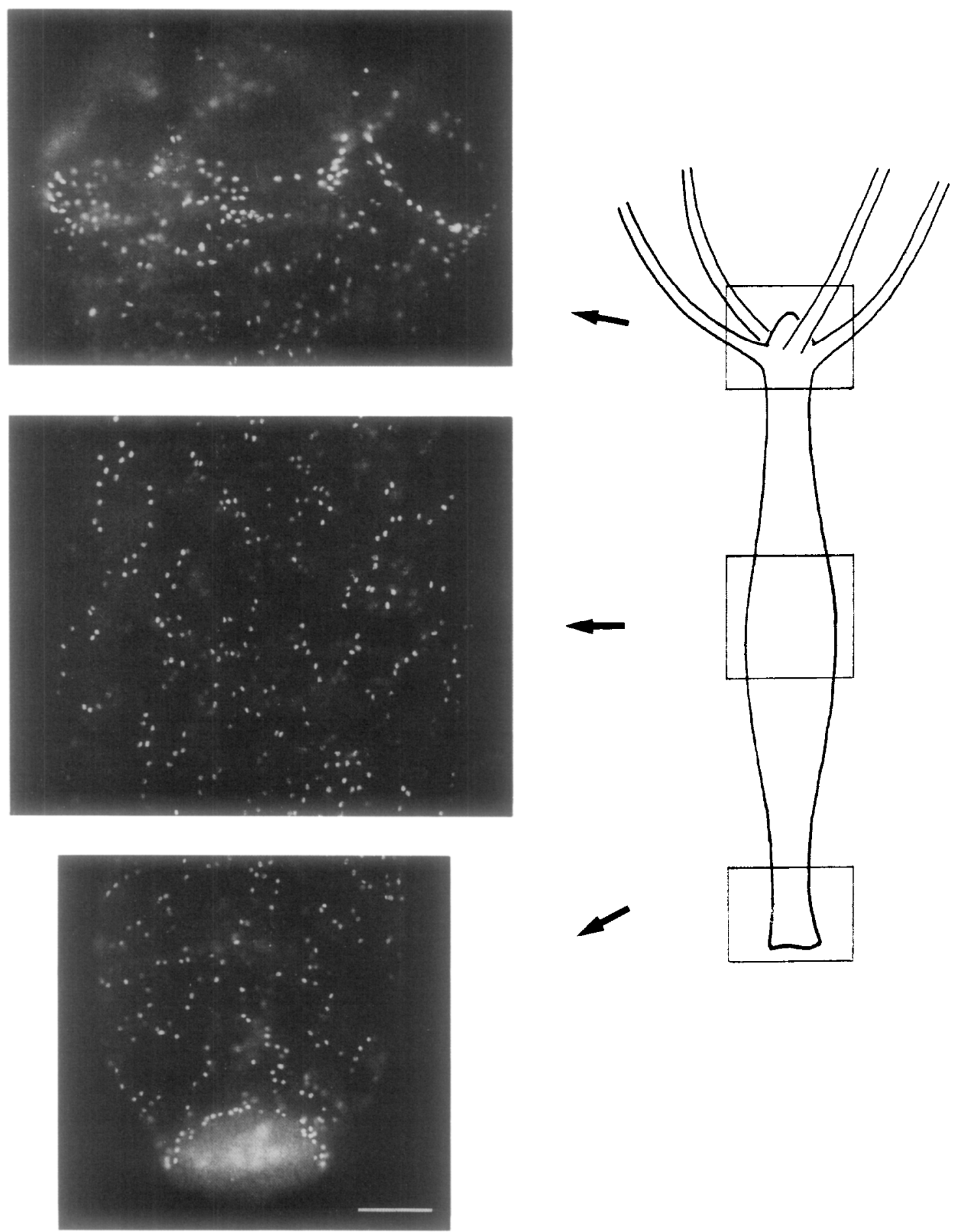

FIG. 1. Micrograph of the Brdu staining pattern in epithelial polyps of Hydra magnipapillata (sf-1). Animals were pulse labeled with Brdu, ethanol fixed, and processed for Brdu visualization using indirect immunofluorescence; bar indicates $400 \mu \mathrm{m}$.

of tentacles formed a relatively sharp ring (Fig. 1). Camera lucida drawings showed that labeled $S$ phase cells at the base of the tentacles were essentially free of nematocytes. More distally located G2 cells contained nema- tocytes. The border between peduncle and pedal disc was also marked in some animals by a sharp ring of labeled cells (Fig. 1), comparable to the ring at the site of tentacle insertion in the head region. 


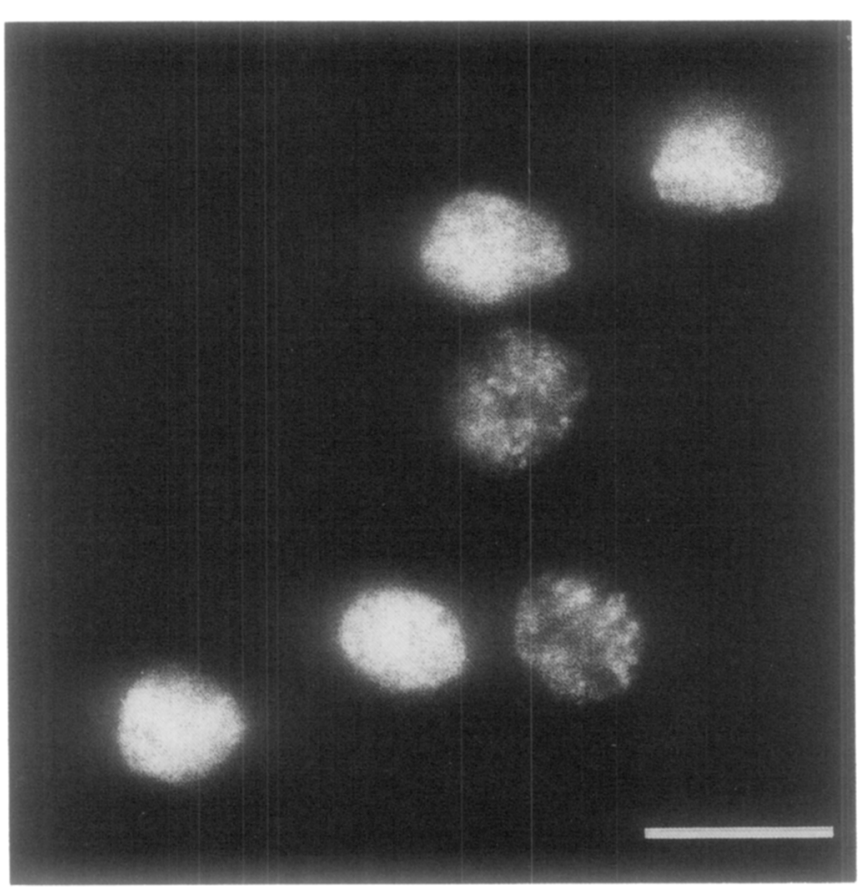

FIG. 2. Micrograph of three Brdu-labeled daughter cell pairs in the lower gastric region of an epithelial polyp. Animals were pulse labeled with Brdu and the incorporation of Brdu was visualized in whole mounts by indirect immunofluorescence (FITC). Bar indicates $10 \mu \mathrm{m}$.

\section{Diurnal Fluctuations in Spatial Pattern of Labeled Epithelial Cells in Daily Fed Animals}

Feeding induces partial synchrony in the epithelial cell population of hydra (Campbell, 1967b; David and Campbell, 1972). Analysis of the labeling index by the Brdu whole mount technique indicated that changes in the labeling index occurred primarily in the gastric region and not in the head and lower peduncle (Figs. 3A and 3B). Six hours after feeding the gastric region was essentially free of S phase epithelial cells (Fig. 3B); 12$18 \mathrm{hr}$ after feeding Brdu-labeled cells were distributed homogeneously over the entire gastric region (Fig. 3C). By comparison, the number of $\mathrm{S}$ phase cells in the head and lower peduncle did not change significantly after feeding (Figs. 3A-C). This was confirmed in macerated cell preparations which demonstrated a constant labeling index of 0.17 in the head region at all times after feeding (Fig. 4A). By comparison, the labeling index in the gastric region in the same animals decreased to 0.08 shortly after feeding and then increased sharply to 0.20 by $12 \mathrm{hr}$ after feeding (Fig. 4B).

Previous work has shown that epithelial cells in starved animals continue cycling but with a $1.5-2$-fold longer cycle time (Bosch and David, 1984). When 8-day starved polyps were labeled with Brdu the labeling in- dex of the head region was not markedly different from that in daily fed animals (Fig. 4A). By comparison, the labeling index in the gastric region decreased from an average value of 0.15 in well-fed polyps to a value of 0.09 in starved polyps (Fig. 4B), consistent with the longer cell cycle in these animals. The micrograph in Fig. 5 illustrates that labeled cells in starved polyps form a gradient with the highest concentration of labeled cells in the head.

\section{Epithelial Cell Cycling during Bud Formation}

We investigated the Brdu labeling pattern during bud formation by pulse-labeling polyps with buds at various stages of development. Polyps were selected from a daily fed culture using the bud stage classification of Otto and Campbell (1977a). The earliest stage of bud formation (stage 3) was characterized by a noticeably increased level of Brdu-labeled epithelial cells (Fig. 6A). This increase in labeled cells became more pronounced at stage 4 when the bud had elongated. In stage 5 buds the distal region of the bud exhibited a higher density of Brdu cells than the rest of the bud (Fig. 6B). In the following stage 6 , the first tentacle rudiments develop in this region (Fig. 6C). At stage 7 the base of the bud adjacent to the parent became slightly constricted (Fig. 6D) and a ring of tightly packed Brdu-labeled cells appeared in this region at stage 8 (Fig. $6 \mathrm{E}$ ). This increase of labeled cells preceded formation of the basal disc, which became visible as a translucent zone at stage 9 .

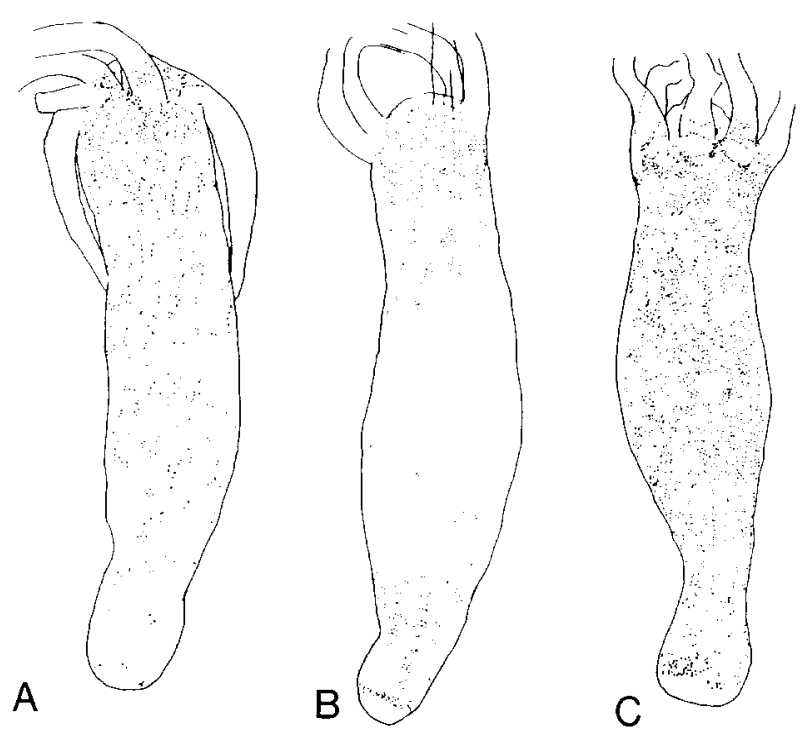

FIG. 3. Changes in the pattern of epithelial cell proliferation after a feeding stimulus. Polyps were pulse labeled 0 (A), 6 (B) and $12 \mathrm{hr}$ (C) after feeding, processed for Brdu localization with FITC, and representative animals were documented by camera lucida drawings (stages at the same magnification). 


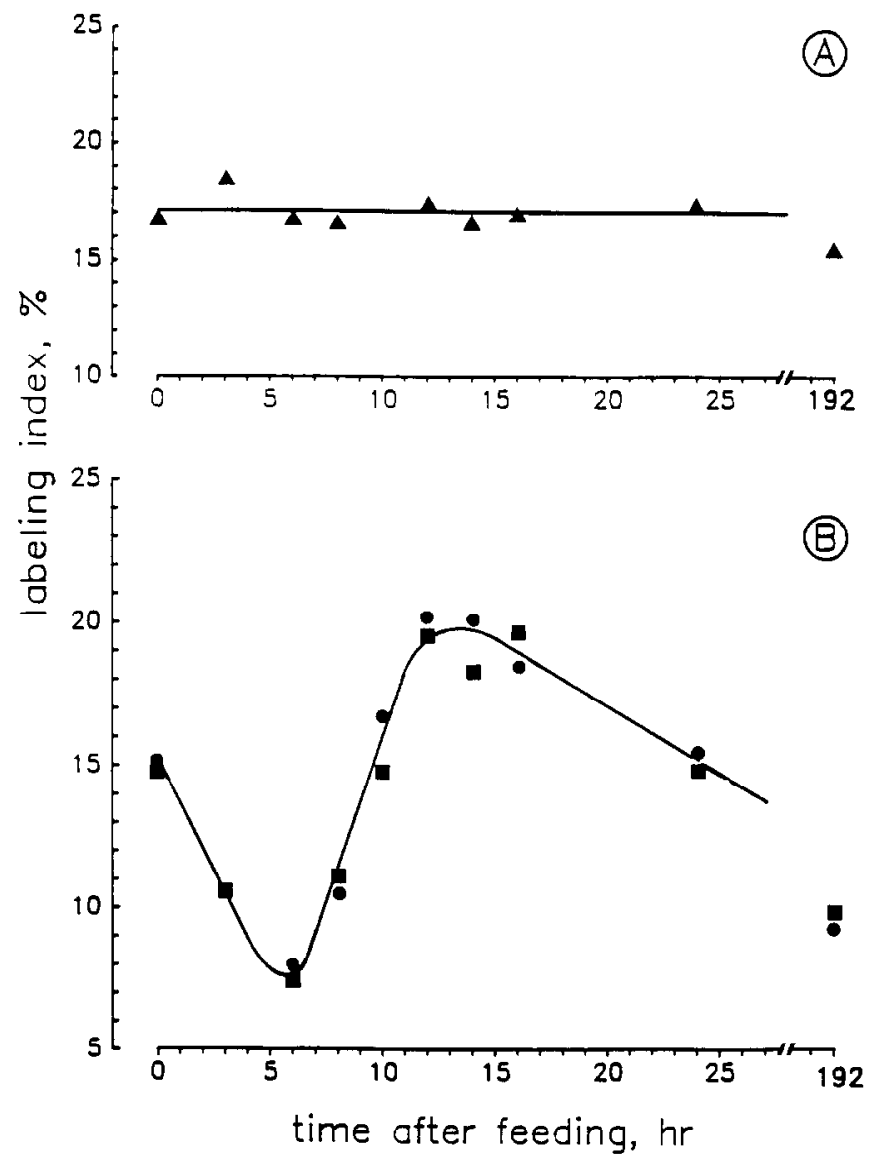

FIG. 4. Fluctuation of the labeling index after a feeding stimulus in head (A) and gastric tissue (B). After feeding polyps were pulse labeled with Brdu at the times indicated and the fraction of labeled cells was determined by indirect immunocytochemistry on macerated cell preparations of the isolated head ( $\bullet)$, upper gastric region $(\bullet)$, and lower gastric region ( $\boldsymbol{\omega})$.

During all stages of bud formation the gastric region of the developing bud appeared to have a higher density of labeled cells than the gastric region of the parent. To measure this change quantitatively we determined the labeling index of epithelial cells in macerates of developing buds and in the surrounding gastric tissue. Figure $7 \mathrm{~A}$ demonstrates that the labeling index increased sharply from 0.17 to 0.27 within the first $10 \mathrm{hr}$ of bud formation (i.e., stage 4). By comparison, the labeling index of epithelial cells in the surrounding gastric tissue was 0.17 . The labeling index remained high in all bud stages although it decreased slowly to 0.23 by stage 9 .

To follow the size increase in developing buds quantitatively we determined the total number of epithelial cells in buds at various stages. Figure 7B shows that the number of epithelial cells increased rapidly from 1000 to 5000 within the first $10 \mathrm{hr}$ (stage 4) and then more slowly from 5000 to 10,000 between 10 and $70 \mathrm{hr}$ of bud

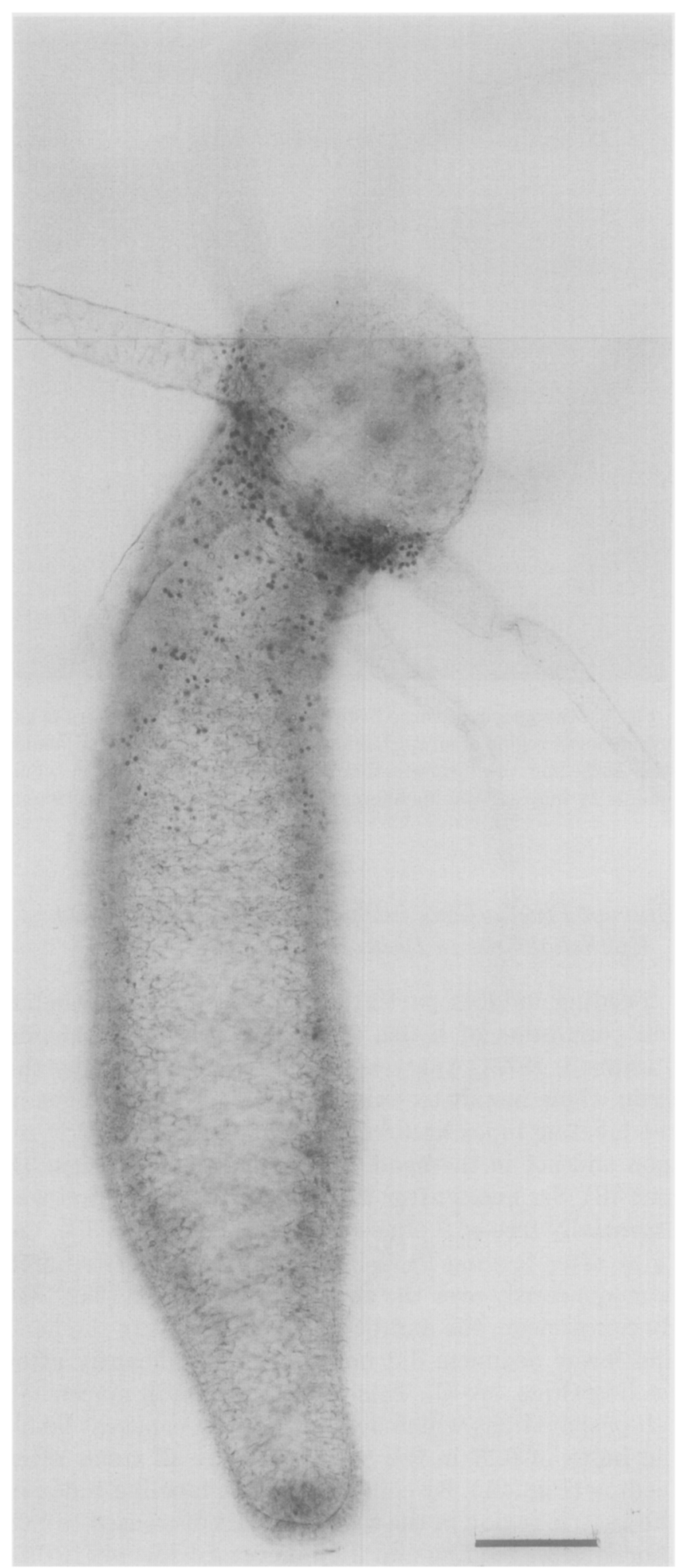

FIG. 5. Brdu labeling pattern of a starved epithelial polyp of $H y d r a$ magnipapillata (sf-1). The animal was pulse labeled with Brdu, ethanol fixed, and processed for Brdu visualization by indirect immunocytochemistry; bar indicates $400 \mu \mathrm{m}$. 

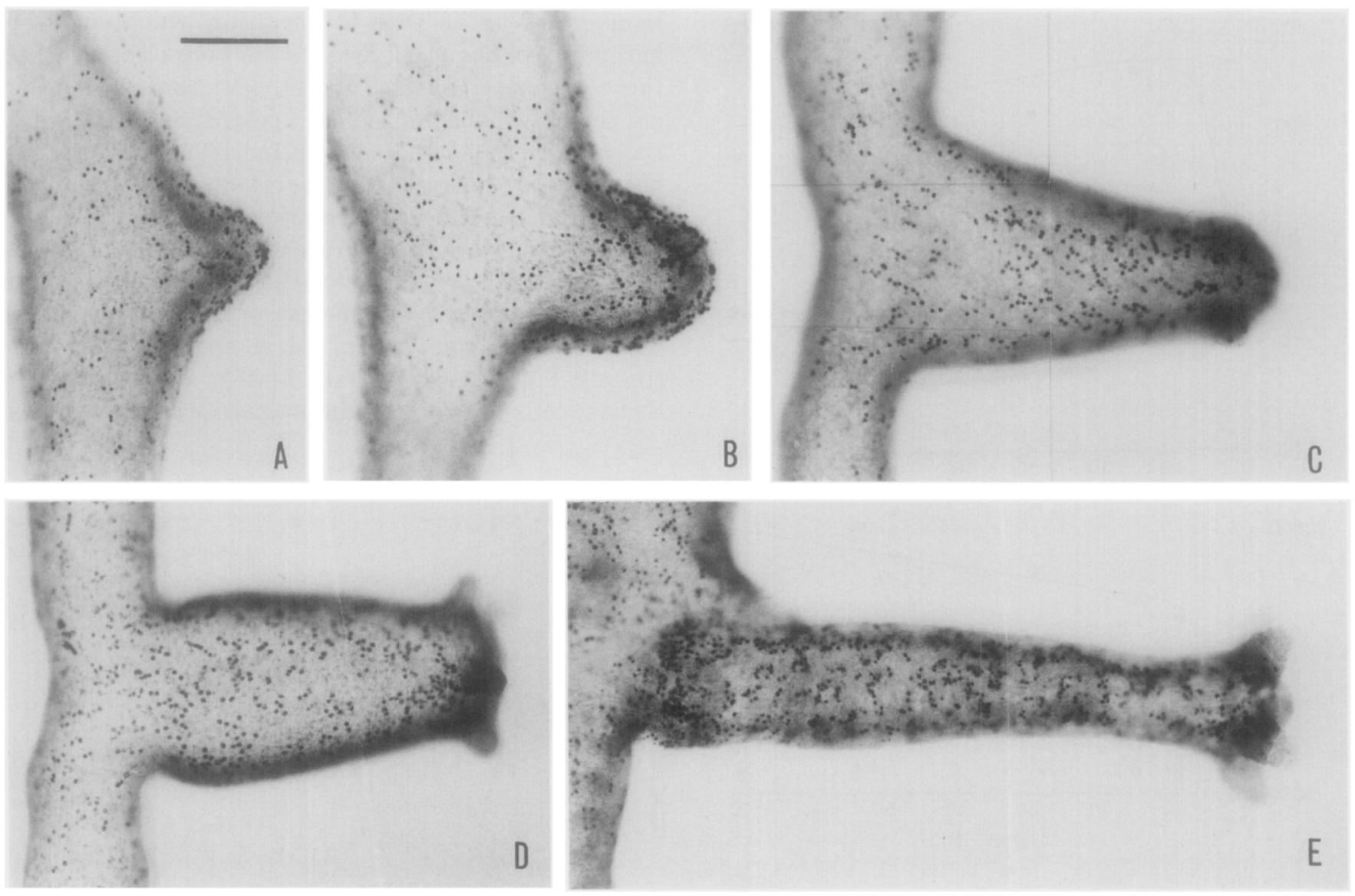

FIG. 6. Micrographs of the pattern of epithelial cell proliferation during bud formation. Polyps at various stages of bud formation were pulse labeled with Brdu and processed for indirect immunocytochemistry. (A) Bud stages 3-4, (B) bud stage 5, (C) bud stage 6, (D) bud stage 7, (E) bud stages 8-9. Classification of bud stages is according to Otto and Campbell (1977a). Bar indicates $250 \mu \mathrm{m}$.

formation. The rapid increase in cell number is due primarily to movement of parental tissue into the bud while the slow increase is due to proliferation of epithelial cells in the developing bud (see Discussion).

\section{Epithelial Cell Cycling during Head Regeneration}

The pattern of Brdu labeling during head regeneration was analyzed by removal of the head region at $60-$ $70 \%$ body length (head $=100 \%$ ) and pulse labeling the regenerates with Brdu at various times after head removal. Figure $8 \mathrm{~A}$ demonstrates that the labeling index of epithelial cells decreased from 0.16 to 0.07 in the regenerating tip (distal $20 \%$ of regenerate) within $12 \mathrm{hr}$ after head removal and increased again at $18 \mathrm{hr}$, reaching a value of 0.22 at $30 \mathrm{hr}$. By comparison, the labeling index in the lower gastric region changed only slightly during the first $12 \mathrm{hr}$ of regeneration and was not markedly different from the labeling index in the gastric region of nonregenerating control animals (Fig. 8B).

Whole mount preparations of Brdu labeled regenerates illustrated dramatic changes in the spatial pattern of cycling cells during regeneration (Fig. 9). Twelve hours after head removal the regenerating tip was completely free of $S$ phase cells creating the visual impression of an "empty zone" (Fig. 9). By $30 \mathrm{hr}$ after head removal the pattern of labeling had completely changed: the regenerating tip was now more strongly labeled than the gastric tissue (Fig. 9). This increase in the number of $\mathrm{S}$ phase cells occurred $18-20 \mathrm{hr}$ before the first tentacle rudiments appeared.

To follow the kinetics of this change in the labeling pattern we also scored the fraction of regenerates displaying an "empty" (Fig. 10A) or a "full" zone (Fig. 10B) at regenerating tips. The fraction of animals with "empty" tips began to increase at $6 \mathrm{hr}$ after head removal and reached a maximum of $100 \%$ at $12 \mathrm{hr}$ (Fig. 11A). The first animals with an increased density of $\mathrm{S}$ phase cells in the regenerating tip appeared at $20 \mathrm{hr}$ after head removal; by $40 \mathrm{hr}$ after head removal $100 \%$ of the regenerates had a higher density of labeled cells in the regenerating tip (Fig. 11B). There is some overlap of the two curves between 20 and $30 \mathrm{hr}$ after head removal 


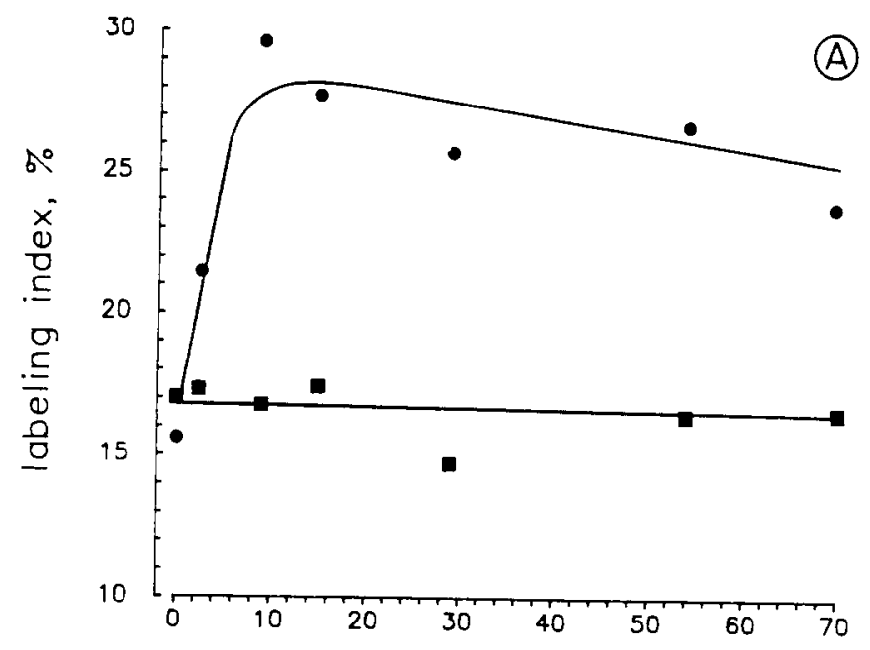

numbers of hydra with a resolution which could not heretofore be achieved. Two results were striking: First, there is a spatial pattern of cell populations with different cell cycle behavior in hydra polyps. Second, the spatial pattern is correlated with morphogenesis and appears to be controlled by morphogenetic signals involved in head and foot formation.

The pattern is not easy to see in well-fed animals since the cycling behavior of epithelial cells is strongly affected by feeding. Nevertheless, it could be visualized when animals were examined at specific times after feeding. Figure 3 shows that $6 \mathrm{hr}$ after feeding very few $\mathrm{S}$ phase cells were present in the gastric region, whereas

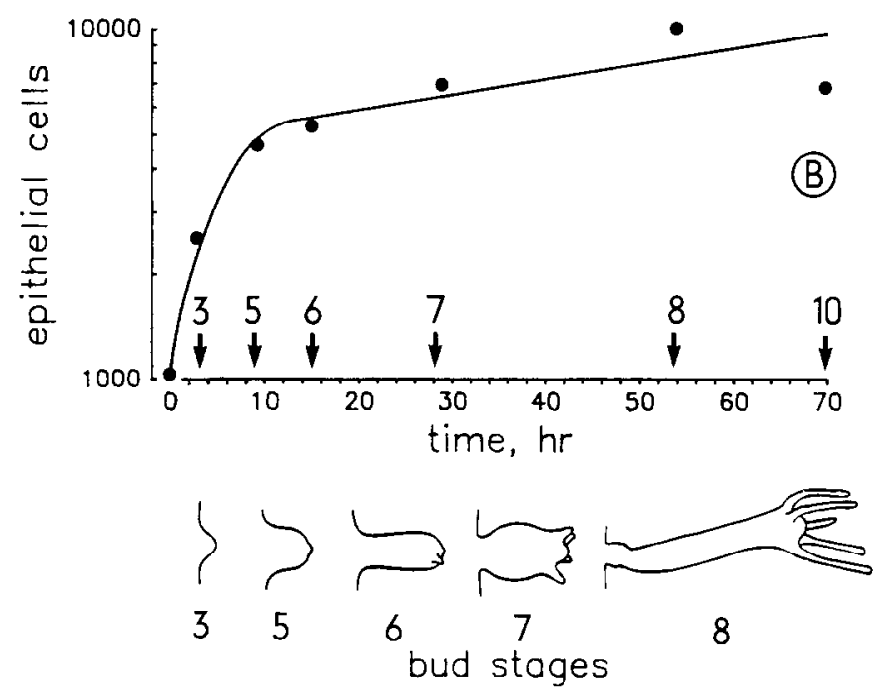

FIG. 7. Changes in the labeling index (A) and increase in total number of epithelial cells (B) during bud formation. The timing of bud stages $3,5,6,7,8$, and 10 is indicated by arrows (B). Bud stages $3,5,6,7$, and 8 were redrawn from Otto and Campbell (1977a). Twenty polyps at each stage of bud formation were pulse labeled with Brdu, thereafter the young bud $(\bullet)$ and the surrounding gastric tissue (E) were isolated and the fraction of labeled cells was determined by indirect immunocytochemistry of macerated cells (A); in the same experiment the total number of epithelial cells in the bud was counted (B).

probably resulting from differences in the regeneration time of individual animals.

The first animals with newly differentiated tentacles appeared at $36 \mathrm{hr}$ after head removal; by $60 \mathrm{hr}$ after head removal $100 \%$ of the regenerates had differentiated tentacles (Fig. 11B).

\section{DISCUSSION}

\section{Pattern of Epithelial Cell Cycling}

Use of the Brdu labeling technique has permitted the observation of spatial patterns of cycling cells in large
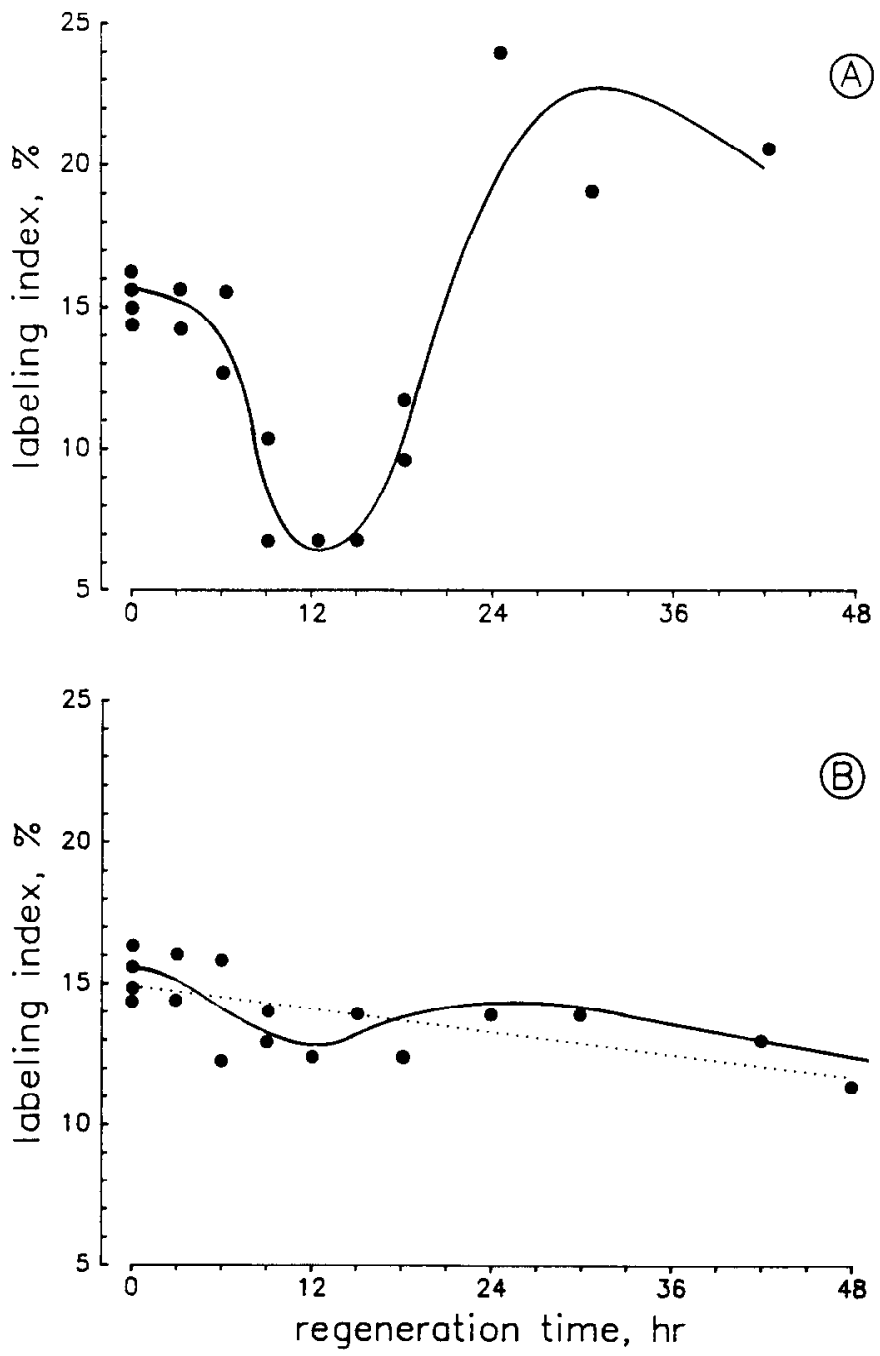

FIG. 8. Fluctuation of the labeling index during head regeneration. Polyps were cut at $60-70 \%$ body length and pulse labeled with Brdu after head removal at the times indicated. Tissue of the regenerating tip (distal $\frac{1}{5}$ of the regenerating animal) (A) and the lower gastric region (B) was isolated and the labeling index was determined on macerated cells by indirect immunocytochemistry. The dotted line in (B) represents the calculated regression line. 

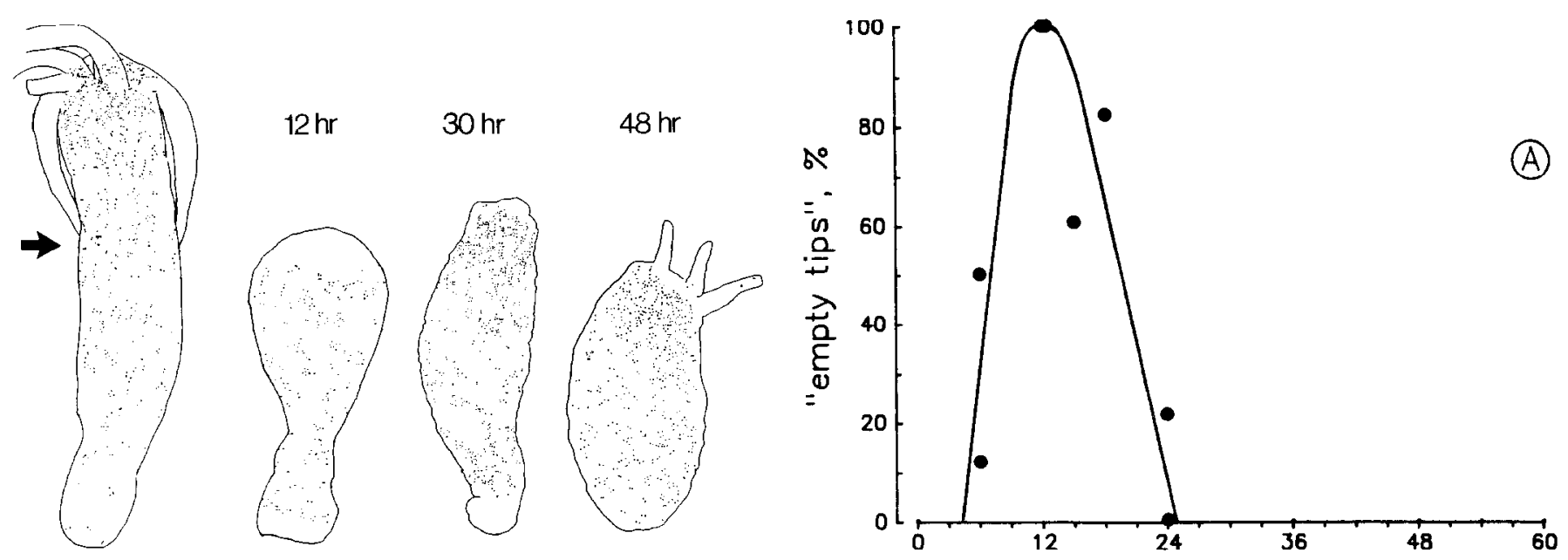

FIG. 9. Changes in the pattern of epithelial cell cycling during head regeneration. Polyps were cut at $60-70 \%$ body length (arrow), pulse labeled with Brdu at the times indicated, and processed for Brdu visualization by indirect immunofluorescence (camera lucida drawings of representative regenerates, all stages at the same magnification).

by $12-18 \mathrm{hr}$ numerous $\mathrm{S}$ phase cells were present. Epithelial cells in the hypostome and subhypostomal region did not exhibit this response to feeding, since a roughly constant number of $S$ phase cells was present at all times in the feeding cycle (Figs. 1, 3, and 4A). Despite this partially synchronized cycling behavior in animals fed once a day, the average cell cycles of cells in head and gastric tissue were not very different. Assuming an $\mathrm{S}$ phase length of $12 \mathrm{hr}$ in well-fed hydra (David and Campbell, 1972), the labeling indices in the head (0.17) and gastric region ( 0.15 average) correspond to cell cycle lengths of 4 and 4.4 days, in good agreement with direct
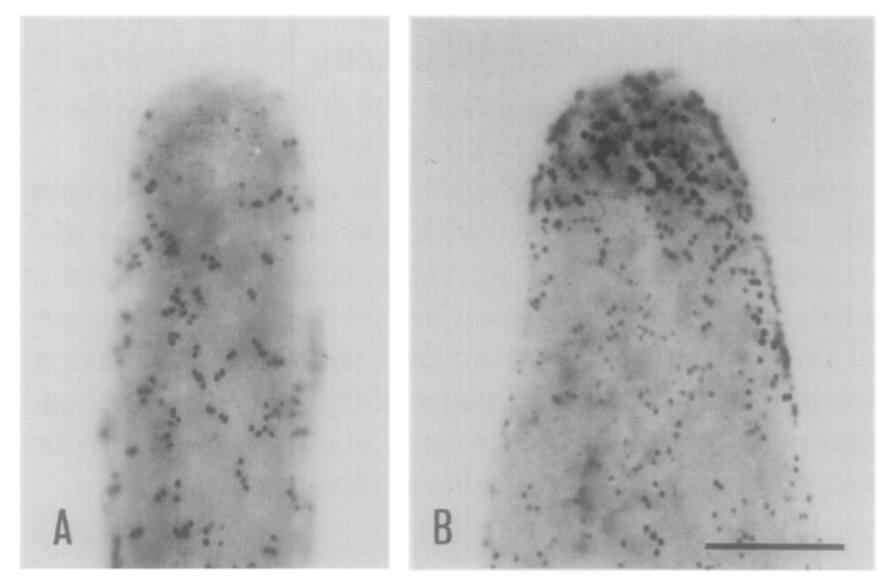

FIG. 10. Micrographs illustrating the pattern of epithelial cell proliferation during head regeneration at $12 \mathrm{hr}$ (A) and at $36 \mathrm{hr}$ (B) after head removal. Polyps were cut at $60-70 \%$ body length pulse labeled with Brdu at 12 and $36 \mathrm{hr}$, respectively, and processed for Brdu visualization by indirect immunocytochemistry. Bar indicates $250 \mu \mathrm{m}$.

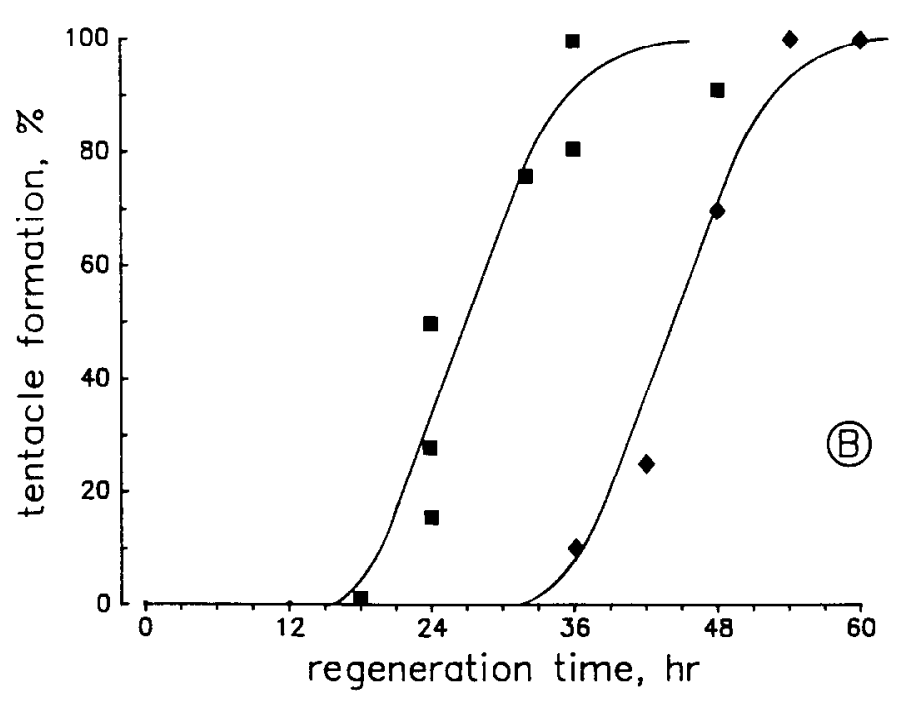

F'IG. 11. Changes in the density of $S$ phase epithelial cells in regenerating head tissue. (A) fraction of regenerates displaying an "empty tip" (decreased density of S phase cells) (-), (B) fraction of regenerates displaying an full tip (increased density of S phase cells) (ם), and fraction of regenerates with regenerated tentacles $(\downarrow)$. Each value represents the average of $30-40$ regenerating animals.

determinations in H. vulgaris (David and Campbell, 1972; Bosch and David, 1984).

The spatial pattern of Brdu-labeled cells became more striking in starved animals. While the number of labeled cells in head tissue remained similar to that in normal animals, the number in the gastric region decreased about twofold (Figs. 4 and 5). Assuming an $\mathrm{S}$ phase of $12 \mathrm{hr}$ similar to that of well-fed animals, then the calculated cell cycle length is 4 days in head tissue and about 8.5 days in gastric tissue. The latter estimate agrees roughly with previous estimates of 7 days (Bosch and David, 1981) and 13 days (Otto and Campbell, 1977b) for the cell cycle in starved animals. If $S$ phase durations of 30-40 hr are assumed (Hermann and Berking, 1987), 
then the calculated cell cycle becomes $20-30$ days which is much longer than the previous observations.

A striking feature of the present results is the biphasic increase in cell number in developing buds. The initial increase in cell number corresponds to a doubling time of 3-5 hr and is so rapid that it can not be simply explained by cell proliferation. Rather, it represents the morphogenetic transfer of parental tissue from the body column into the developing bud (Otto and Campbell, 1977a; Graf and Gierer, 1980). The subsequent increase in epithelial cell number has a doubling time of 55-60 hr (Fig. 7B). Epithelial cells in buds have a labeling index of about 0.27 (Fig. 7A) which corresponds to a cell cycle length of $57 \mathrm{hr}$ assuming a $12-\mathrm{hr} \mathrm{S}$ phase (David and Campbell, 1972). Since this estimate is similar to the observed doubling time, it appears that the second phase of bud formation is dominated by cell proliferation and not by further cell displacement from the body column.

The present results resolve an old controversy concerning the pattern of tissue growth in hydra. McConnell $(1932,1933)$ and Campbell $(1965,1967 a, b)$ observed a roughly uniform distribution of epithelial mitoses along the body column of well-fed animals. By comparison, Burnett (1961), Burnett and Garofalo (1959), and Corff (1971) observed a pattern in which epithelial cell mitoses were more numerous in the distal half of the gastric region. The results reported here indicate that both results can be obtained depending on the timing and feeding state of polyps. It should be emphasized, however, that the cell cycle does not differ greatly between cells in the head and gastric regions and hence, as pointed out by Campbell (1967a,b), the distal body column can not be regarded as a "growth zone."

\section{Signals Affecting Cell Cycle Regulation}

The epithelial cell cycle in hydra has been shown to lack G1 and to have a long and variable G2 (David and Campbell, 1972). The present results on Brdu labeling confirm these observations. Labeled cells occurred as identically labeled pairs (Figs. 1 and 2), indicative of identical position in $\mathrm{S}$ phase and in agreement with a rapid and highly synchronous progression of both daughter cells from mitosis into $S$ phase.

The variable G2 provides a potential target for signals regulating epithelial cell cycling in hydra. Feeding is one such signal. Herrman and Berking (1987) have shown that feeding immediately and transiently inhibits mitosis. The rapid decrease in S phase cells following feeding in Fig. 4 is presumably due to this inhibitory effect. This transient inhibition appears to be the event which synchronizes cell cycling in the gastric region; release of the inhibition then leads to a peak of mitoses $12 \mathrm{hr}$ after feeding. Since cells in the head are not affected by feeding, cycling of these cells must be driven by endogenous signals associated with head tissue (see below).

Head regeneration also causes release of signals inhibiting epithelial cell mitosis (Figs. 8, 9; see also Park et al., 1970, Berking, 1974). Release of the inhibitory signals is local and transient since only cells at the regenerating tip are affected and only for the first $12 \mathrm{hr}$ of regeneration. Thereafter mitosis resumes.

Whether the resumption of mitosis following inhibition hy feeding and inhibition by regeneration is due to decay of the inhibitory effect or to release of a stimulatory signal is not clear. Postulating a stimulatory signal, however, is not necessary since the increased number of labeled cells following inhibition is roughly equal to the number of cells which failed to divide during the period of inhibition. Other aspects of our results do, however, suggest the existence of stimulatory signals driving cells through mitosis. In starved animals more labeled cells are present in the head than in the gastric region, indicative of head-specific signals which stimulate mitosis (Figs. 4 and 5). The increased density of labeled cells in developing buds (Figs. 6 and 7) compared to parental tissue is also indicative of localized signals stimulating mitosis.

Factors which stimulate or inhibit mitosis and thus affect G2 length in hydra have been described. Berking (1974, 1977; Herrmann and Berking, 1987) has described a factor, inhibitor I, which blocks mitosis of epithelial cells. Treatment of hydra with the factor inhibits mitosis almost immediately, indicating that the factor acts late in G2 phase. Removal of the inhibitor leads to a quick resumption of mitotic activity. This factor could well be the signal mediating the inhibitory effects of feeding and regeneration on epithelial cell cycling.

Schaller (1976, 1977; Schaller et al., 1990) has shown that treatment of hydra with low concentrations of a neuropeptide, the head activator, stimulates mitosis in epithelial cells. Stimulation occurs $69 \mathrm{hr}$ after the onset of treatment, indicating that the sensitive phase of the cycle is in G2. Local release of this factor in the head region and in developing buds could lead to the increased level of $S$ phase cells in these regions.

\footnotetext{
We are indebted to T. Sugiyama for supplying the sf1 mutant of Hydra magnipapillata. We thank H. K. MacWilliams and T. Bosch for critically reading the manuscript. Reviews by R. D. Campbell and S. Berking helped significantly to improve an earlier version of the manuscript. This research was supported by the Deutsche Forschungsgemeinschaft by grants to C.N.D. (Da 163-1-3) and T.W.H. (Ho 1088-1-2).
} 


\section{REFERENCES}

BERKING, S. (1974). Nachweis eines morphogenetisch aktiven Hemmstoffs in Hydra attenuata und Untersuchung seiner Eigenschaften und Wirkung. Universität Tübingen, FRG, $\mathrm{PhD}$ thesis.

BERKING, S. (1977). Bud formation in Hydra: Inhibition by an endogeneous morphogen. Wilhelm Roux's Arch. Dev. Biol. 181, 215-225.

Bone, H., and BoDe, P. (1984). Patterning in Hydra. In "Pattern Formation: A Primer in Developmental Biology" (G. Maliacinski and S. V. Bryant, Eds.), Vol. 1, pp. 213-241. MacMillan, New York.

Bosch, T. C. G., and DAvID, C. N. (1984). Growth regulation in Hydra: Relationship between epithelial cell cycle length and growth rate. Dev. Biol. 104, 161-171.

BRYANT, P. J., and Simpson, P. (1984). Intrinsic and extrinsic control of growth in developing organs. Q. Rev. Biol. 59, 387-415.

BURNETT, A. L.20(1961). The growth process in hydra. J. Exp. Zool. 146, 21-84.

BURNETT, A. L. (1966). A model of growth and cell differentiation in Hydra. Am. Nat. 100, 165-190.

BurnetT, A. L., and Garofalo, M. (1959). Growth pattern in the green hydra, Chlorohydra viridissima. Science 131, 160-161.

CAMPBELL, R. D. (1965). Cell proliferation in hydra: An autoradiographic approach. Science 148, 1231-1232.

CAmpBelL, R. D. (1967a). Tissue dynamics of steady state growth in Hydra littoralis. I. Pattern of eell divisions. Dev. Biol. 15, 487502.

CAMPBell, R. D. (1967b). Growth of hydra pattern: Distribution of mitotic cells in H. pseudooligactis. Trans. Am. Microscop. Soc. 86, 169-173.

CAMPBELL, R. D., and DAvid, C. N. (1974). Cell cycle kinetics and development of Hydra altenuata. J. Cell. Sci. 16, 349-358.

Clarkson, S. G., and Wolpert, L. (1967). Bud morphogenesis in hydra. Nature 214, 780-783.

CoRFF, S. (1971). Mitosis and differentiation in hydra morphogenesis. In "Developmental Aspects of the Cell Cycle" (I. L. Cameron, G. M. Padilla, and P. M. Zimmermann, Eds.), pp. 93-125. Academic Press, New York.

DAvID, C. N (1973) A quantitative method for maceration of hydra tissue. Wilhelm Roux's Arch Dev. Biol. 171, 259-268.

DAvid, C. N., and CAMPBELL, R. C. (1972). Cell cycle kinetics and development of Hydra attemuata. I. Epithelial cells. J. Cell Sci. 11, 557568.

Diehl, F. A., and BuRnetT, $\Lambda$. (1965). The role of interstitial cells in the maintenance of hydra. J. Exp. Zool. 158, 283-298.

Dolbeare, F., Gratzner, H., Palla vicini, M. G., and Gray, J. W. (1983). Flow cytometric measurement of total DNA content and incorporated bromodeoxyuridine. Proc. Natl. Acad. Sci. USA 80, 55735577.

Dübel, S., Hoffmeister, S., and Schaller, H. C. (1987). Differentiation pathway of ectodermal epithelial cells in hydra. Differentiation 41, 99-109.

FrEnCH, V. (1984). A model of insect limb regeneration. In "Pattern budding hydra and regulation of regeneration in aggregates. Wilhelm Roux's Arch. Dev. Biol. 188, 141-151.

GratzNer, H. G. (1982). Monoclonal antibody to 5-bromo- and 5-Iododeoxyuridine, a new reagent for detection of DNA replication. Science 218, 474-475.

HerrmanN, K., and Berking, S. (1987). The length of S phase and G2-phase of epithelial cells is regulated during growth and morphogenesis in Hydra attenuata. Development 99, 33-39.

Hobmayer, E., Holstein, T. W., and David, C. N. (1990a). Tentacle morphogenesis in hydra. I. The role of head activator. Development 109, 887-895.

Hobmayer, E., Holstein, T. W., and David, C. N. (1990b). Tentacle morphogenesis in hydra. II. Formation of a complex between a sensory nerve cell and a battery cell. Development 109, 897-904.

Marcum, B. A., FuiJsawa, T., and Sugiyama, T. (1980). A mutant strain (sf-1) containing temperature sensitive interstitial cells. In "Developmental and Cellular Biology of Coelenterates" (P. Tardent and R. Tardent, Eds.), pp. 429-434. Elesevier North-Holland, Amsterdam.

MCCoNNELL, C. H. (1932). Zellteilungen bei Hydra. Mitosen in den epitheliomuskulären Zellen des Entoderms von Hydra. Z. Mikrosk Anat. Forsch. 28, 578-588.

McConNell, C. H. (1933). Mitosis in hydra. Mitosis in the ectodermal epitheliomuscular cells in Hydra. Biol. Bull. 64, 96-102.

OTTO, J. J., and CAMPBELL, R. D. (1977a). Budding in Hydra attenuata: Bud stages and fate map. J. Exp. Zool. 200, 417-428.

OTTO, J. J., and CAMpretL, R. D. (1977b). Tissue economics of hydra: Regulation of cell cycle, animal size and development by controlled feeding rates. $J$. Cell Sci. 28, 117-132.

Park, H., Orthmeyer, A. B., and Blankkenbaker, D. P. (1970). Cell division during regeneration in Hydra. Nature 227, 617-619.

Plickert, G., and Kroiher, M. (1988). Proliferation kinetics and cell lineages can be studied in whole mounts and macerated tissue by means of Brdu/anti-Brdu technique. Development 103, 791-794.

Schalder, H. C. (1976). Action of head activator as a growth hormone in hydra. Cell Differ. 5, 5-11.

SCHALLER, H. C.20(1977). Action of a morphogenetic substance from hydra. In "Molecular Control of Proliferation and Differentiation" (J. Papaconstantinov, and W. J. Rutter, Eds.), pp. 231-241. Academic Press, New York.

Schaller, H. C., HoffmanN, M., and Javois, L. C. (1990). Effect of head activator on proliferation, head specific determination and differentiation of epithelial cells in hydra. Differentiation 43, 157164

SugiYma, T., and FuiJSAWA, T. (1977). Genetic analysis of developmental mechanism in $H y d r a$. Sexual reproduction of Hydra magnipapillata and isolation of mutants. Dev. Growth Differ. 19, 187-200.

SUMmerbell, D., LEWIS, H., and WOLPERT, L. (1973). Positional information in chick limb morphogenesis. Nature 244, 492-496.

WeBster, G., and HamiLton, S. (1972). Budding in hydra: The role of cell multiplication and cell movement in bud initiation. J. Embryol. 